\title{
Engaging leader - Engaged employees? A cross-lagged study on employee engagement
}

\author{
Irina Nikolova ${ }^{\text {a, b, * }}$, Wilmar Schaufeli ${ }^{\text {b, d }}$, Guy Notelaers ${ }^{c}$ \\ a Open University of The Netherlands, Valkenburgerweg 177, 6419 AT, Heerlen, the Netherlands \\ ${ }^{\mathrm{b}} \mathrm{KU}$ Leuven, Dekenstraat 2, 2500, Leuven, Belgium \\ ${ }^{\mathrm{c}}$ University of Bergen, Department of Psychosocial Science, Bergen, Norway \\ d Utrecht University, Department if Psychology, The Netherlands
}

\section{A R T I C L E I N F O}

\section{Article history:}

Received 8 July 2018

Received in revised form

14 January 2019

Accepted 28 February 2019

Available online 1 March 2019

\section{Keywords:}

Engaging leadership

Employee work engagement

Job resources

Learning opportunities

Autonomy

\begin{abstract}
A B S T R A C T
The goal of this study is to provide a cross-lagged examination of the relationships between engaging leadership, job resources and employee work engagement. We propose a mediation model and we postulate that engaging leadership can increase perceptions of three specific job resources (i.e. autonomy, support from colleagues and opportunities for learning and development) which theoretically correspond to the three facets of engaging leadership (i.e., inspiring, connecting and strengthening, respectively). Subsequently, in keeping with the extant body of Job Demands-Resources (JD-R) research, we link job resources to employee work engagement. Our hypotheses were tested on data collected at two time-points - T1 $(\mathrm{N}=759)$ and $\mathrm{T} 2(\mathrm{~N}=273)$-from employees working for a hotel chain in the Netherlands. In line with our expectations, engaging leadership showed a significant cross-lagged relationship with autonomy and support from colleagues, but did not predict learning opportunities and work engagement across time. While we formulated specific hypotheses, we also tested reversed causation relationships. We found no direct effect from engaging leadership on employee work engagement, however, the reversed effect was significant; employee perceptions of engaging leadership were shaped by their own engagement experiences. Importantly, engaged employees at T1 reported more job resources at T2. By providing a cross-lagged examination of our model, we showed that engaging leaders as well as employees' positive affective state of being engaged, are essential to shaping a resourceful work context. A comprehensive view on the triggers and outcomes of work engagement and engaging leadership is needed, as the traditional unidirectional cause-effect rationale fails to explain how these concepts relate to one another and to employee experiences of job resources.
\end{abstract}

(c) 2019 Elsevier Ltd. All rights reserved.
Researchers and practitioners widely agree that sustaining high employee work engagement should be a top priority for organisations. In pursuit of such a desirable goal, many companies rely on their first-line managers to craft a resourceful work environment that is conducive to employee work engagement (Nielsen, Randall, Yarker, \& Brenner, 2008). But how can managers fulfil such demanding expectations?

This study will offer insights into this matter by investigating a specific leadership style (i.e. engaging leadership) that is particularly suited for enhancing work engagement, which is defined as 'a positive, fulfilling work-related state of mind that is characterized

\footnotetext{
* Corresponding author. KU Leuven, Dekenstraat 2, 2500, Leuven, Belgium.

E-mail addresses: irina.nikolova@ou.nl (I. Nikolova),wilmar.schaufeli@kuleuven. be (W. Schaufeli), Guy.Notelaers@uib.no (G. Notelaers).
}

by vigor, dedication and absorption' (Schaufeli, Salanova, GonzálezRomá, \& Bakker, 2002, p. 74). Specifically, we will examine the potential of the engaging leader to increase employee perceptions of job resources and to subsequently boost individuals' engagement in their work. We selected three types of job resources (i.e. social support from colleagues, autonomy and learning opportunities) because they are known to be crucial for employee motivation, performance and well-being at work (Fernet, Austin, \& Vallerand, 2012; Hakanen, Schaufeli, \& Ahola, 2008; Hu, Schaufeli, \& Taris, 2011). We also focused on the motivational processes that engaging leadership evokes, drawing upon literature about leadership and job characteristics.

Despite initial evidence revealing synchronous associations between engaging leadership, job characteristics and work engagement (Schaufeli, 2015), there is still a lack of empirical work 
that examines the causal links between engaging leadership, job resources and employee work engagement across time (c.f. Skakon, Nielsen, Borg, \& Guzman, 2010). This study provides a cross-lagged examination of the causal relationships between these concepts by testing the proposed assumptions on two-wave data obtained from hotel employees across a one-year period.

Our paper adds to current knowledge in two ways. First, it integrates insights from leadership literature (e.g. Schaufeli, 2015) with those from the job characteristics field. That field includes several overlapping theoretical frameworks, such as the Job Demands-Resources model (Demerouti, Bakker, Nachreiner, \& Schaufeli, 2001), the Job Demand-Control (-Support) model (Karasek \& Theorell, 1990) and the Job Characteristics model (Oldham, 1996).

Second, our paper proposes a mediation model that explores the relationships between engaging leadership, job resources and work engagement, as they evolve over a one-year period (see Fig. 1). This responds to a recently raised scholarly concern that extant research has almost exclusively focused on temporary-synchronous links between leadership and employee work engagement, leaving issues such as variability of the effects across time and causality of the relationships unexplored (see literature review of Carasco-Saul, Kim, \& Kim, 2015). There is a need to investigate how leadership styles influence employee outcomes across time because the dynamics between leaders and their followers are usually complex, unfold over time and may vary across time. Prior research (e.g. Carasco-Saul et al., 2015) has suggested that, owing to their motivational properties, positive leadership styles may positively affect employee work engagement in the short term but may have the opposite effect in the long term because employees might feel overpowered when they are continuously challenged and motivated by their manager. Therefore, it is important to gain more insights into the temporal effects of engaging leadership on employee outcomes.

\section{Theory development}

\subsection{Leadership and employee work engagement}

A rapidly growing body of empirical evidence obtained from diverse samples (i.e. among heterogeneous groups or groups with one specific occupation) has unambiguously demonstrated that favourable leadership behaviours or styles can be beneficial to employee work engagement. A recent meta-analysis (DeCuypere \&
Schaufeli, 2018) found moderate to strong associations between work engagement and various favourable leadership styles, including transformational, authentic, ethical, empowering and servant leadership. In addition, a recent review of the literature on (predominantly transformational) leadership style and employee work engagement (Carasco-Saul et al., 2015) revealed highly consistent findings across most of the studies. Altogether, the results of these overviews indicate a clear pattern: specifically, transformational leaders are able to successfully motivate employees, thereby contributing to a higher level of employee work engagement (e.g. Ghadi, Fernando, \& Caputi, 2013; Vincent-Höper, Muser, \& Janneck, 2012).

Empirical support for this positive relationship also comes from a dairy study conducted among Dutch consultants (Tims, Bakker, \& Xanthopoulou, 2011), which showed that transformational leaders can enhance employee work engagement on a day-to-day basis. Using a multilevel, multi-source design and employees from different cultural backgrounds, Zhu, Avolio, and Walumbwa (2009) came to a similar conclusion: transformational leaders in South Africa enhanced employee work engagement. In another multilevel study, Tuckey, Bakker, and Dollard (2012) found that - at the group level - empowering leadership among brigade captains had a positive association with the engagement of volunteer firefighters at the individual level. Finally, investigating the potential additive effects of transformational and fair leadership with respect to employee work engagement, Perko, Kinnunen, Tolvanen, and Feldt (2016) established that these two leadership styles are interchangeable when applied as means to foster employee work engagement.

Taken together, these findings from studies that used different research methodologies show that transformational leadership and other favourable leadership behaviours are positively linked to employee work engagement. Below we argue that job resources might play a crucial role in explaining this link.

\subsection{The concept of engaging leadership}

In this study, we focus on engaging leadership as a precursor to employee perceptions of job resources and work engagement. We chose to study an engaging leadership style because, from a theoretical perspective, engaging leaders may have a profound impact on employee work engagement and may show meaningful connections with specific job resources (Schaufeli, 2015). This is

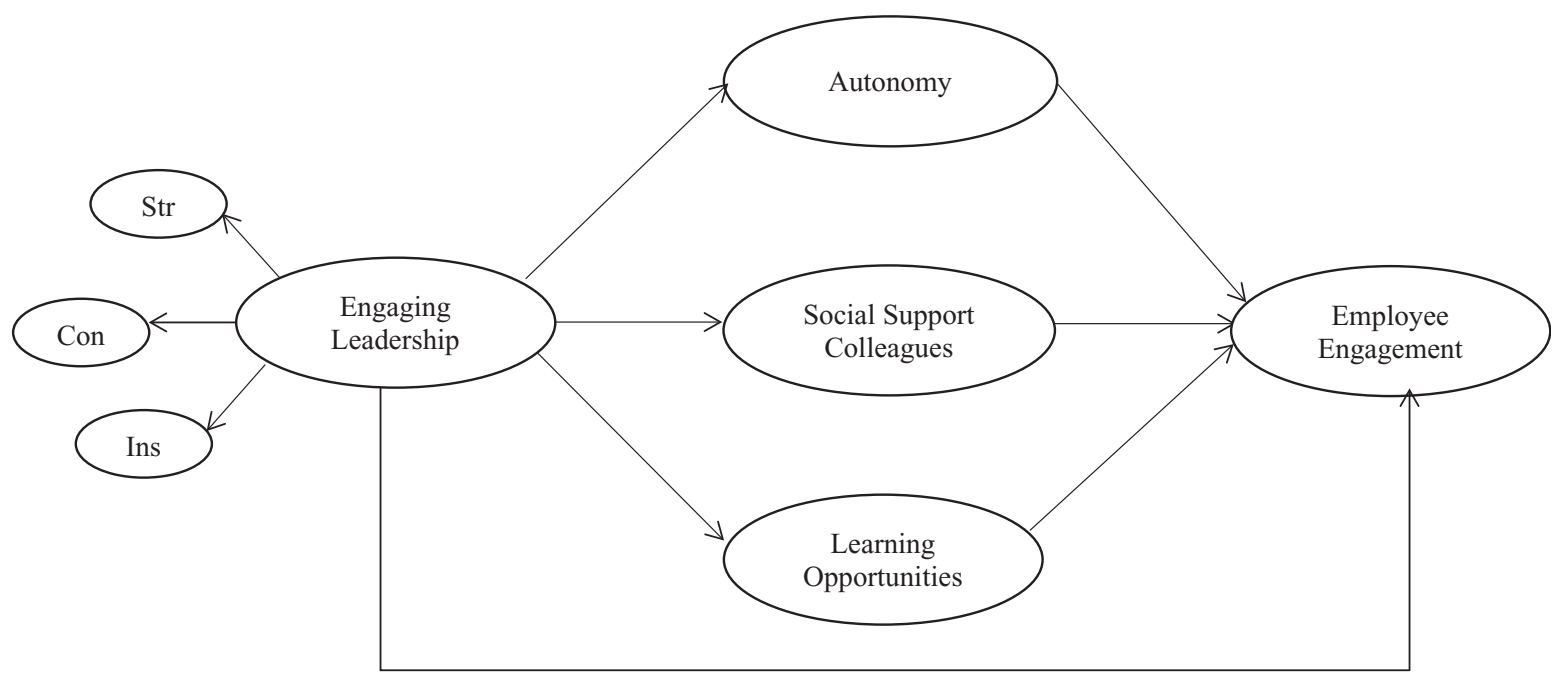

Fig. 1. Conceptual model. Note: Str = Strengthening leadership, Con = Connecting leadership and Ins = Inspiring leadership. 
because the notion of engaging leadership (Schaufeli, 2015) strongly draws upon Self-Determination Theory (SDT; Deci \& Ryan, 2000), which identifies three innate psychological needs as the core drivers of an individual's optimal functioning at work. Specifically, SDT links the needs for autonomy (i.e. feeling in control), competence (i.e. feeling effective) and relatedness (i.e. feeling loved and cared for) to healthy functioning of employees. Moreover, SDT posits that the degree to which these needs are being met (Ryan \& Deci, 2001) is predictive of employee work engagement (i.e. high degrees of energy, focus and persistence).

In short, Schaufeli (2015) suggests that an engaging leader can increase and sustain employee work engagement by satisfying their basic psychological needs. Typically, this is achieved by nurturing employee inspiration (e.g. increasing their enthusiasm for their vision and plans, making them feel that they contribute to the organisation's mission), strengths (e.g. granting freedom and responsibility, delegating tasks) and sense of connectedness (e.g. encouraging collaboration, promoting a high team spirit). Subsequently, inspiring, strengthening and connecting behaviours of the leader are expected to directly contribute to the fulfilment of employees' needs for autonomy (experiencing a sense of control because they are contributing to an important goal), competence (experiencing a sense of mastery because of delegated tasks) and relatedness (experiencing a connection with other team members because they are encouraged to collaborate and bond). Only when these basic needs are fulfilled are employees likely to achieve high levels of work engagement, as shown in a study by Van den Broeck, Vansteenkiste, De Witte, and Lens (2008). Our study does not measure psychological need satisfaction as such, but the engaging leadership measure is based on its premises.

The concept of engaging leadership overlaps with other favourable leadership styles to the extent that they are all geared towards stimulating employee's motivation, well-being and positive organisational behaviour. However, each leadership style also has its unique feature. For instance, transformational leadership aims at transforming individual employees' mindsets towards achieving organisational goals (Bass \& Riggio, 2006), while ethical leadership (Brown, Treviño, \& Harrison, 2005) focuses on normative behaviour. Servant leadership (Liden, Wayne, Liao, \& Meuser, 2014) focuses on being altruistic as a leader and attuned to the needs and development of employees, authentic leadership (Walumbwa, Wang, Wang, Schaubroeck, \& Avolio, 2010) focuses on being selfaware and authentic, and empowering leadership (Zhang \& Bartol, 2010) focuses on empowering employees. Engaging leadership differs from these positive leadership concepts because it is theorybased and rooted in SDT, and because it focuses exclusively on engaging followers by satisfying their basic psychological needs (Hetland, Hetland, Schou Andreassen, Pallesen, \& Notelaers, 2011).

Comparing engaging leadership with transformational leadership, by far the most researched and well-accepted leadership concept, reveals some overlap but also some notable differences. Transformational leadership (Bass, 1985) emphasises four types of leadership behaviours: (1) inspirational motivation (i.e. talking optimistically and enthusiastically about the future and articulating a compelling vision); (2) idealised influence (i.e. role modelling, articulating high expectations and confidence in followers); (3) individualised consideration (i.e. coaching and mentoring, and listening to followers' concerns); and (4) intellectual stimulation (i.e. encouraging followers to challenge existing approaches, reframe problems and think in new ways).

Admittedly, some similarities might be found between engaging and transformational leadership, as both styles focus on a leader's ability to activate employees and optimise their functioning. However, a closer look at the theoretical background and the dimensions of the two leadership styles promptly reveals several

\section{differences.}

In essence, the concept of engaging leadership departs from the notion of the leader as a source of motivation for employees and accordingly builds upon the tenets of SDT - one of the most acknowledged theories of motivation (Schaufeli, 2015). Transformational leadership, however, is not rooted in a motivational theory; it taps into leadership facets that positively activate employees (e.g. stimulating their creativity, coaching and role modelling). Moreover, the three dimensions of engaging leadership are designed to match the three basic needs of employees and thus emphasise different aspects of the leader's behaviours compared to transformational leadership facets. For instance, whereas engaging leaders assign a particular importance to the social aspect of employee functioning (by recognising the individual's need for belonging), transformational leaders do not seem to attend to this need. Unlike transformational leadership that emphasises role modelling (idealised influence), coaching and mentoring (individualised consideration) and creativity (intellectual stimulation), engaging leadership focuses on fostering social connections and employee autonomy.

Altogether, the validity of the transformational leadership framework has been heavily criticised, even to the extent that some authors suggest going 'back to the drawing board' (Van Knippenberg \& Sitkin, 2013). Three major criticisms are voiced: (1) a clear conceptual definition is lacking; (2) no causal model is specified; and (3) the most frequently used measurement tools are unsound. For these reasons and because of the importance of motivation theories for explaining motivational processes and engagement, in this study we chose to examine engaging leadership as an antecedent of employee-perceived resources and work engagement.

\subsection{Leadership and employee work engagement: the role of job resources}

Research on the mechanisms that may explain how leadership styles positively affect employee and organisational outcomes have identified job characteristics as a mediator (Nielsen et al., 2008; Piccolo \& Colquitt, 2006; Schaufeli, 2015). For instance, a study by Ghadi et al. (2013) among full-time Australian employees revealed a positive link between transformational leadership and employee work engagement, which was partially mediated by meaningful work. In a similar manner, Bamford, Wong, and Laschinger (2013) found that the perceived person-job fit is a crucial mediator in the relationship between authentic leadership and employee work engagement. The study of Piccolo and Colquitt (2006) corroborated previous findings by convincingly showing that job resources serve as a mediator between transformational leadership and employee motivation. Confirming the mediating capacity of job resources, Nielsen et al. (2008) found that role clarity, meaningful work and opportunities for development serve as key links in the relationship between transformational leadership and positive employee outcomes; in fact, job resources fully mediate this relationship.

Altogether, the above evidence indicates the importance of job resources for the relationship between positive leadership styles and employee positive outcomes (e.g. engagement). Yet, most of these studies (except for Nielsen et al., 2008) only explored synchronous links (due to their cross-sectional design), so virtually no evidence exists about the direction of the effects. To overcome this common pitfall, in this study we tested the influences of engaging leadership on employee-perceived level of job resources and work engagement across a one-year time lag. 


\subsection{The current study}

We set out to provide empirical evidence for the mediation of specific job resources (that reflect the fulfilment of the three SDT needs) that may explain the relationship between engaging leadership and employee work engagement. Since we start from the idea that an engaging leader influences employee work engagement by increasing specific job resources, we assume that mediation mechanisms may play a key role in this relationship.

From a theoretical point of view, because of their unique position of influence, leaders are ideally placed to steer employees' perceptions about their work context. Leadership facets such as coaching and support have the potential to influence the way employees appraise their job resources (Breevaart, Bakker, Hetland, \& Hetland, 2014; Lee \& Ashforth, 1996; Schaufeli \& Bakker, 2004). A positive leadership style (e.g. engaging leadership) that motivates employees and helps them feel safe and supported will likely unlock positive emotions. Such positive emotions may expand the individual's thought-action repertoire (broaden-and-build theory; Fredrickson, 2001), resulting in enhanced perceptions of the available resources.

Moreover, good leaders are expected to nurture a resourceful work environment that can enhance employee work motivation (Shuck \& Herd, 2012). Put in terms of engaging leadership, inspiring leaders provide their followers with job control so that they experience a sense of autonomy and may contribute to the common work goals in a personal and meaningful way. Furthermore, strengthening leaders provide their followers with opportunities for growth and development so that they experience a sense of mastery and may improve their competencies. And finally, engaging leaders connect their followers by promoting social support among them so that they feel psychologically safe and cared for. Taken together, we reason that engaging leadership has an indirect effect on work engagement through increasing specific job resources, which, in turn, may satisfy followers' basic psychological needs.

More specifically, in this study, we propose that two of the three core aspects of engaging leadership behaviour may be particularly linked to employees' experiences of autonomy. That is, engaging leaders who inspire employees to work towards certain challenging goals need to give employees sufficient job control in handling the challenges associated with their tasks (Schaufeli, 2015). Similarly, strengthening leaders need to provide their employees with job control so they can develop a sense of competence and self-efficacy.

In a similar vein, all three facets of engaging leadership may be key to employee experiences of the extent to which learning opportunities are afforded to them in the work context. To be able to learn and develop their professional potential, employees need a leader who inspires them to strive towards mastery and who motivates them to contribute to a common and meaningful goal (Nielsen et al., 2008).

Additionally, the strengthening aspect of engaging leadership is essential to employee perceptions of learning opportunities, as such opportunities are best detected and utilised when employees experience sufficient support and freedom of choice to act on any opportunities (Schaufeli, 2015). Employees who do not have a strengthening leader may feel that they are not being trusted with important tasks and are denied access to learning opportunities. Leaders who strengthen their employees by actively encouraging them to search for and engage in professional learning opportunities might successfully satisfy their need for competence.

The third aspect of engaging leadership - connecting leadership - could also be associated with employee perceptions of learning opportunities. A connecting leader encourages teamwork and a collaborative environment where the exchange of ideas and knowledge thrives. Such work contexts are doubtlessly highly conducive to professional development, as one of the most important sources of learning at work is the immediate social environment (Boud \& Middleton, 2003).

Finally, each of the three facets of engaging leadership can be linked to the employees' experiences of social support. The idea of inspiring leadership, for instance, holds that leaders who are capable of evoking enthusiasm among their employees to strive together towards a meaningful, common goal will enhance their perceptions of being embedded in a positive social context. Alternatively, strengthening leaders can also affect employees' experiences of their immediate social environment at work. By granting freedom and responsibility, and by encouraging employees to express their own opinions, strengthening leaders shape an environment that is conducive to open communication and mutual trust. Such an environment is likely to nurture positive relationships among the employees and to enhance perceptions of social support (Schaufeli, 2015). Last, and perhaps most evident, is the association between connecting leadership and the employees' perceptions of social support. Connecting leaders affect their employees' sense of relatedness with one another by encouraging collaboration and promoting a high team spirit (Schaufeli, 2015). Such leaders strengthen the social ties and sense of support among employees.

Altogether, the above reasoning illustrates how each facet of engaging leadership may potentially impact the three proposed job resources. Considering that engaging leadership seems to operate as one overarching (i.e. second-order) concept (see Schaufeli, 2015) with three underlying, closely related dimensions (i.e. inspirational, strengthening and connecting leadership), we hypothesise that relationships evolve from engaging leadership (viewed as a compound latent construct) through the three job resources to employee work engagement. In line with this key proposition of this study, we formulate the following hypotheses:

Hypothesis 1. Engaging leadership has a positive cross-lagged impact on job resources (i.e. social support, autonomy and learning opportunities).

Hypothesis 2. Job resources have a positive cross-lagged impact on employee work engagement.

\section{Method}

\subsection{Participants and procedure}

The data were obtained by means of online questionnaires sent to all employees of a hotel chain operating in the Netherlands. Data collection took place in the spring of 2015 (T1) and one year later in 2016 (T2). At both times, the online surveys included basically the same questions. Employees from all functions represented in the hotels were invited to take part in the survey.

Of the 1055 questionnaires sent at T1, 452 were filled in and returned, which yielded a response rate of $42.8 \%$. $45 \%$ of respondents were male, and on average they had been working in their current position for 5.5 years. The average age of the surveyed employees in $\mathrm{T} 1$ was 36.6 years $(\mathrm{SD}=12.2)$.

Of the 905 questionnaires sent at T2, 580 were filled in and returned, which yielded a response rate of $64 \%$. The data of 273 of the 580 respondents at T2 could be linked to T1, as they filled out the survey twice. Of the final longitudinal panel, $48 \%$ were male, and on average they had been working in their current position for 6.6 years. The majority of the employees who filled in the questionnaire at T2 worked in a clerical function (59.3\%), while less than half of them were blue-collar workers (40.7\%). 


\subsection{Measures}

Engaging leadership. We measured engaging leadership with a scale developed by Schaufeli (2015), which includes three subdimensions: inspiring, strengthening and connecting leadership. For all three sub-dimensions, answers were given on a 5-point Likert scale ranging from (1) fully disagree to (5) fully agree. Each of the three sub-dimensions was measured with three items respectively. An example item of inspiring leadership is: My direct supervisor gives employees the feeling that they are working on something important. An example of strengthening leadership is: My direct supervisor gives employees sufficient freedom and responsibility. An example of connecting leadership is: My direct supervisor encourages collaboration among the member of our team.

Job resources. To measure job resources, we included three scales (autonomy, learning opportunities and social support from colleagues) that are based on the Questionnaire on the Experience and Evaluation of Work (QEEW; van Veldhoven \& Meijman, 1994). QEEW is often used in the Netherlands for carrying out psychosocial risk analyses. For each of the three scales, answers were given on a 5-point Likert scale ranging from (1) never to (5) always. Autonomy was measured with three items. For example: You can decide yourself how you conduct your work. Learning opportunities was measured with three items. For example: My job offers me sufficient opportunities for personal growth and development. Social support from colleagues was measured with three items. For example: I can ask my colleagues for help when I need it.

Employee work engagement was measured with three items selected from the Dutch version of the Utrecht Work Engagement Scale (UWES; Schaufeli, Shimazu, Hakanen, Salanova, \& De Witte, 2017). For example: I am enthusiastic about my work.

Controls. Age, gender, seniority, occupational position and weekly hours of work were included as covariates to control for alternative explanations; these variables were selected because existing studies (e.g. Bakker, Demerouti, \& Schaufeli, 2005; Bakker, Hakanen, Demerouti, \& Xanthopoulou, 2007) underscore the importance of controlling for demographics when studying job resources and work engagement. We tested the study model twice: with and without control variables. As the results obtained from the model(s) with the control variables did not differ considerably from results obtained from the model(s) where no controls were incorporated, for parsimony reasons and in line with the recommendation of Spector and Brannick (2011), we reported only the models without control variables.

Cronbach's alphas for the all study variables are presented in Table 1.

\subsection{Analyses}

To test the hypothesised models, we used structural equation modelling (SEM) with the Mplus software package, version 7.4 (Muthén \& Muthén, 2010). We employed a full panel design including all study variables at T1 and T2. Based on theoretical and empirical arguments (see Schaufeli, 2015), we modelled engaging leadership as a second-order latent construct, which is composed of three latent sub-dimensions (inspirational, strengthening and connecting leadership). Furthermore, we included each of the three mediators (i.e. autonomy, learning opportunities and social support) and the dependent variable (i.e. employee work engagement) as separate latent constructs.

To examine our hypotheses, which relied on data collected at two points in time, we followed the analytical approach recommended by Cole and Maxwell (2003) and Taris and Kompier (2006). This approach allows testing partial mediation using a two-wave design (see also Hakanen et al., 2008; Philippaers, De Cuyper, Forrier, Vander Elst, \& De Witte, 2016). Cole and Maxwell (2003) proposed testing two pairs of cross-lagged analyses, which allows a comparison among several competing models (i.e. stability, causal, reversed and reciprocal models). Testing partial mediation by using two-wave data implies: (1) examining the causal relationship between the predictor and the mediator; and (2) testing the relationship between the mediator and the outcome.

Following the recommended analyses, we specified several competing models: a stability model $\left(\mathrm{M}_{\text {stabil }}\right)$ including only autoregressive paths between each pair of latent constructs across time; a causality model ( $\left.\mathrm{M}_{\text {causal }}\right)$ including autoregressive and causal relationships (for $\mathrm{M} 1_{\text {causal }}$ between engaging leadership and job resources, and for $\mathrm{M} 2_{\text {causal }}$ between job resources and work engagement); a reversed causation model ( $\left.\mathrm{M}_{\text {revers}}\right)$ including autoregressive and the reversed to the hypothesised relationships (for $\mathrm{M} 1_{\text {revers }}$ between job resources and engaging leadership, and for $\mathrm{M} 2$ revers between work engagement and job resources); $\mathrm{a}$ reciprocal model $\left(M_{\text {recipr }}\right)$ including all paths as specified in $M_{\text {stabil, }}$ $\mathrm{M}_{\text {causal }}$ and $\mathrm{M}_{\text {revers }}$ (in $\mathrm{M} 1_{\text {recipr }}$ we included $\mathrm{M} 1_{\text {stabil, }} \mathrm{M} 1_{\text {causal }}$ and $\mathrm{M} 1_{\text {revers, }}$ and in $\mathrm{M} 2_{\text {recipr }}$ we included $\mathrm{M} 2_{\text {stabil, }} \mathrm{M} 2_{\text {causal }}$ and $\mathrm{M} 2_{\text {revers }}$ ).

Several fit indices were used to assess model fit; comparative fit index (CFI), Tucker-Lewis index (TLI) and the root mean square error of approximation (RMSEA), commonly used for evaluating goodness-of-fit in SEM. Values exceeding 0.90 for CFI and TLI and lower than or equal to 0.08 for RMSEA indicate an acceptable fit (Byrne, 2013). In addition, we used an $\chi^{2}$-difference test to compare the four alternative models (stability, causal, reversed and reciprocal).

Table 1

Cronbach's Alpha, means, standard deviations and correlations among the study variables.

\begin{tabular}{|c|c|c|c|c|c|c|c|c|c|c|c|c|c|c|c|c|}
\hline Scale & $M$ & $S D$ & 1 & 2 & 3 & 4 & 5 & 6 & 7 & 8 & 9 & 10 & 11 & 12 & 13 & 14 \\
\hline 1. Insp. leadership T1 & 3.51 & 0.91 & $(.93)$ & .60 & .68 & .50 & .80 & .57 & .13 & .18 & .47 & .32 & .36 & .38 & .32 & .26 \\
\hline 2. Insp. leadership T2 & 3.46 & 0.92 & & $(.93)$ & .45 & .71 & .51 & .86 & .21 & .40 & .38 & .52 & .31 & .48 & .35 & .49 \\
\hline 3. Strengt. leadership T1 & 3.90 & 0.74 & & & $(.86)$ & .57 & .66 & .45 & .25 & .24 & .38 & .22 & .38 & .36 & .37 & .23 \\
\hline 4. Strengt. leadership T2 & 3.84 & 0.75 & & & & $(.82)$ & .41 & .70 & .24 & .35 & .36 & .39 & .28 & .45 & .29 & .38 \\
\hline 5. Connec. leadership T1 & 3.70 & 0.77 & & & & & $(.86)$ & .54 & .10 & .13 & .40 & .27 & .43 & .35 & .32 & .27 \\
\hline 6. Connec. leadership T2 & 3.68 & 0.90 & & & & & & $(.90)$ & .15 & .28 & .39 & .49 & .34 & .48 & .33 & .47 \\
\hline 7. Autonomy $\mathrm{T} 1$ & 4.00 & 0.81 & & & & & & & $(.78)$ & .64 & .17 & .18 & .12 & .27 & .34 & .32 \\
\hline 8. Autonomy T2 & 4.00 & 0.84 & & & & & & & & $(.81)$ & .22 & .30 & .14 & .36 & .34 & .46 \\
\hline 9. Learning Opport. T1 & 3.53 & 0.93 & & & & & & & & & $(.90)$ & .60 & .34 & .29 & .51 & .43 \\
\hline 10. Learning Opport. T2 & 3.40 & 0.90 & & & & & & & & & & (.89) & .24 & .36 & .43 & .58 \\
\hline 11. Social Support T1 & 3.76 & 0.84 & & & & & & & & & & & $(.79)$ & .56 & .39 & .28 \\
\hline 12. Social Support T2 & 3.66 & 0.90 & & & & & & & & & & & & $(.82)$ & .41 & .49 \\
\hline 13. Engagement T1 & 3.71 & 0.80 & & & & & & & & & & & & & $(.80)$ & .67 \\
\hline 14. Engagement T2 & 3.63 & 0.85 & & & & & & & & & & & & & & $(.83)$ \\
\hline
\end{tabular}

Note. T1 ( $\mathrm{N}=452), \mathrm{T} 2(\mathrm{~N}=273)$; Correlations: $r<0.11, p=n s ; r>0.12<0.17, p<.05 ; r>0.17, p<.001$. 
Table 2

Fit statistics for testing cross-lagged relationships between engaging leadership and job resources $(\mathrm{N}=273)$.

\begin{tabular}{|c|c|c|c|c|c|c|c|c|c|}
\hline Model & Model description & $\chi^{2}$ & df & RMSEA & CFI & TLI & Model comparison & $\Delta \chi^{2}$ & $\Delta \mathrm{df}$ \\
\hline $\mathrm{M}_{\text {mes }}$ & Measurement & 1202.63 & 767 & .05 & .95 & .94 & & & \\
\hline Mdir & Direct effect of EL on JR & 367.72 & 229 & .05 & .97 & .97 & & & \\
\hline \multicolumn{10}{|c|}{ Cross-lagged relationships between engaging leadership (EL) and job resources (JR) } \\
\hline M1 $1_{\text {stabil }}$ & Stability & 922.81 & 554 & .05 & .95 & .94 & & & \\
\hline M1 $1_{\text {causal }}$ & Causality (M1 $1_{\text {stabil }}+$ EL on JR) & 907.49 & 551 & .05 & .95 & .95 & M1 $1_{\text {stabil }}$ vs $M 1_{\text {causal }}$ & $15.32^{* *}$ & 3 \\
\hline $\mathrm{M} 1_{\text {revers }}$ & Reversed $\left(\mathrm{M} 1_{\text {stabil }}+\mathrm{JR}\right.$ on EL) & 918.45 & 551 & .05 & .95 & .95 & $\mathrm{M} 1_{\text {stabil }}$ vs $\mathrm{M} 1_{\text {revers }}$ & 4.36 n.s. & 3 \\
\hline \multirow[t]{3}{*}{ M1 $1_{\text {recipr }}$} & Reciprocal (M1 $\left.1_{\text {causal }}+\mathrm{M} 1_{\text {revers }}\right)$ & 904.10 & 548 & .05 & .95 & .95 & M1 $1_{\text {stabil }}$ vs $M 1_{\text {recipr }}$ & $18.71^{* *}$ & 6 \\
\hline & & & & & & & $\mathrm{M} 1_{\text {causal }} \mathrm{Vs} \mathrm{M} 1_{\text {recipr }}$ & 3.39 n.s. & 3 \\
\hline & & & & & & & $\mathrm{M} 1_{\text {revers }}$ Vs $\mathrm{M} 1_{\text {recipr }}$ & $14.35^{* *}$ & 3 \\
\hline
\end{tabular}

${ }^{* *} \mathrm{p}<.01 ;{ }^{* * *} \mathrm{p}<.001$

\section{Results}

Before testing the hypotheses, we conducted attrition analyses to assess whether dropout between $\mathrm{T} 1$ and $\mathrm{T} 2$ might have been predicted by some of the study variables at T1 or by the demographics (Goodman \& Blum, 1996). Logistic regression and crosstab analyses were used to test whether the key study variables (engaging leadership, the three job resources and work engagement) and the demographics (gender and seniority) were linked to dropout at T2. The results showed that, except for autonomy, dropout was randomly distributed. We found that employees who perceived less autonomy in their job dropped out more often at T2 than those who perceived more autonomy $\left(O R=1.32, p<.05 ; \chi^{2}\right.$ (6) $=24.14, p<.001$ ).

Table 1 presents the scales' Cronbach's alphas, means, standard deviations, inter-correlations and test-retest reliabilities of the study variables.

Primary to the mediation analyses, we tested a measurement model that specifies the relationships between the observed and the latent constructs. This is necessary to establish whether each study measure loads on the intended factor (Byrne, 2013). In line with our expectations, each item loaded on the intended factor. Loadings varied from 0.66 to 0.91 (fit statistics showed an acceptable fit: $\chi^{2}(768)=1471.79, p<.001$, RMSEA $=0.06, C F I=0.92$, $\mathrm{TLI}=0.91)$.

Fit statistics of the competitive models obtained from the SEM analyses are presented in Table 2. First, the results showed that both the measurement model $\left(\mathrm{M}_{\text {mes }}\right)$ and the direct effect model $\left(\mathrm{M}_{\mathrm{dir}}\right.$ with autoregressive paths and a direct effect between engaging leadership and work engagement) had a good fit to the data (Table 2). However, against our expectations and based on the results from $\mathrm{M}_{\mathrm{dir}}$, there was no significant relationship between T1 engaging leadership and T2 work engagement ( $\beta=0.04, p=.48)$.

Second, we compared alternative models examining crosslagged relationships between the predictor 'engaging leadership' and the mediator 'job resources' (Table 2). Compared to the stability model ( $\left.\mathrm{M} 1_{\text {stabil }}\right)$, the causal model ( $\mathrm{M} 1_{\text {causal }}$ which includes autoregressive and causal effects between T1 engaging leadership and T2 job resources) showed a better fit to the data $\left(\Delta \chi^{2}=15.32, \Delta d f=3\right.$, $p<.01)$. The reversed causation model, however, did not show any improvement in fit compared to the stability model $\left(\Delta \chi^{2}=4.36\right.$, $\Delta d f=3$, n.s.). In addition, the reciprocal model fitted the data better than the stability model $\left(\Delta \chi^{2}=18.71, \Delta d f=6, p<.01\right)$. However, its fit did not improve compared to the causal model $\left(\Delta \chi^{2}=3.39\right.$, $\Delta d f=3$, n.s). Taken together, this indicates that the causal model in which $\mathrm{T} 1$ engaging leadership predicts $\mathrm{T} 2$ job resources is the model that best represents the data.

Third, as reported in Table 3, the causal model (T1 job resources and T2 work engagement) did not fit the data better than the stability model $\left(\Delta \chi^{2}=4.14, \Delta d f=3, n . s\right)$. In contrast, the reversed model $\left(\Delta \chi^{2}=27.53, \Delta d f=3, p<.001\right)$ fit the data better than the stability model; whereas the reciprocal model fit the data better than the stability model $\left(\Delta \chi^{2}=18.71, \Delta d f=6, p<.01\right)$. However, its fit was not better than that of the reversed model $\left(\Delta \chi^{2}=2.38\right.$, $\Delta d f=3, n . s)$, indicating that the reversed model was the model that best represents the data.

Fig. 2 depicts autoregressive and cross-lagged relationships ( $\left.M 1_{\text {causal }}\right)$ between engaging leadership at $\mathrm{T} 1$ and the three job resources (social support, autonomy and learning opportunities) at T2. In line with our expectation, engaging leadership at T1 had a positive cross-lagged effect on social support $(\beta=0.24, p<.001)$ and autonomy $(\beta=0.14, p=.02)$ at T2. However, it did not predict learning opportunities $(\beta=0.05, p=.43)$.

Fig. 3 shows autoregressive and cross-lagged relationships $(\mathrm{M} 2$ revers $)$ between work engagement at $\mathrm{T} 1$ and the three job resources at T2. Specifically, we established positive cross-lagged relationships between engagement at $\mathrm{T} 1$ and each of the three job resources at T2 (for social support: $\beta=0.27, p<.001$; for autonomy: $\beta=0.20, p=.001$; and for learning opportunities: $\beta=0.22$, $p=.001)$.

In addition, we tested cross-lagged relationships between engaging leadership and engagement. While we found no support for the hypothesised direct effect from engaging leadership on engagement $(\beta=.04, p=.48$ ), the reversed effect was significant $(\beta=0.14, p=.014)$.

In sum, the results from the analyses showed that engaging

Table 3

Fit statistics for testing cross-lagged relationships between job resources and engagement $(\mathrm{N}=273)$.

\begin{tabular}{|c|c|c|c|c|c|c|c|c|c|}
\hline Model & Model description & $\chi^{2}$ & df & RMSEA & CFI & TLI & Model comparison & $\Delta \chi^{2}$ & $\Delta \mathrm{df}$ \\
\hline \multicolumn{10}{|c|}{ Cross-lagged relationships between engaging leadership job resources (JR) and engagement (ENG) } \\
\hline $\mathrm{M} 2_{\text {stabil }}$ & Stability & 347.52 & 224 & .05 & .97 & .96 & & & \\
\hline $\mathrm{M} 2$ causal & Causality ( $\mathrm{M} 2_{\text {stabil }}+\mathrm{JR}$ on ENG) & 343.38 & 221 & .05 & .97 & .96 & $\mathrm{M} 2_{\text {stabil }}$ vs $\mathrm{M} 2_{\text {causal }}$ & 4.14 n.s. & 3 \\
\hline $\mathrm{M} 2_{\text {revers }}$ & Reversed ( $\mathrm{M} 2_{\text {stabil }}+$ ENG on JR) & 319.99 & 221 & .04 & .97 & .97 & $\mathrm{M} 2_{\text {stabil }}$ vs $\mathrm{M} 2_{\text {revers }}$ & $27.53^{* * *}$ & 3 \\
\hline \multirow[t]{3}{*}{$\mathrm{M} 2_{\text {recipr }}$} & Reciprocal ( $\left.\mathrm{M}_{\text {causal }}+\mathrm{M}_{\text {revers }}\right)$ & 317.61 & 218 & .04 & .97 & .97 & $\mathrm{M} 2_{\text {stabil }}$ vs $\mathrm{M} 2_{\text {recipr }}$ & $18.71^{* *}$ & 6 \\
\hline & & & & & & & $\mathrm{M} 2_{\text {causal }} \mathrm{Vs} \mathrm{M} 2_{\text {recipr }}$ & $29.91^{* * *}$ & 3 \\
\hline & & & & & & & $\mathrm{M} 2_{\text {revers }} \mathrm{Vs} \mathrm{M} 2_{\text {recipr }}$ & 2.38 n.s. & 3 \\
\hline
\end{tabular}

${ }^{* *} \mathrm{p}<.01 ;{ }^{* * *} \mathrm{p}<.001$. 
Time 1

Time 2

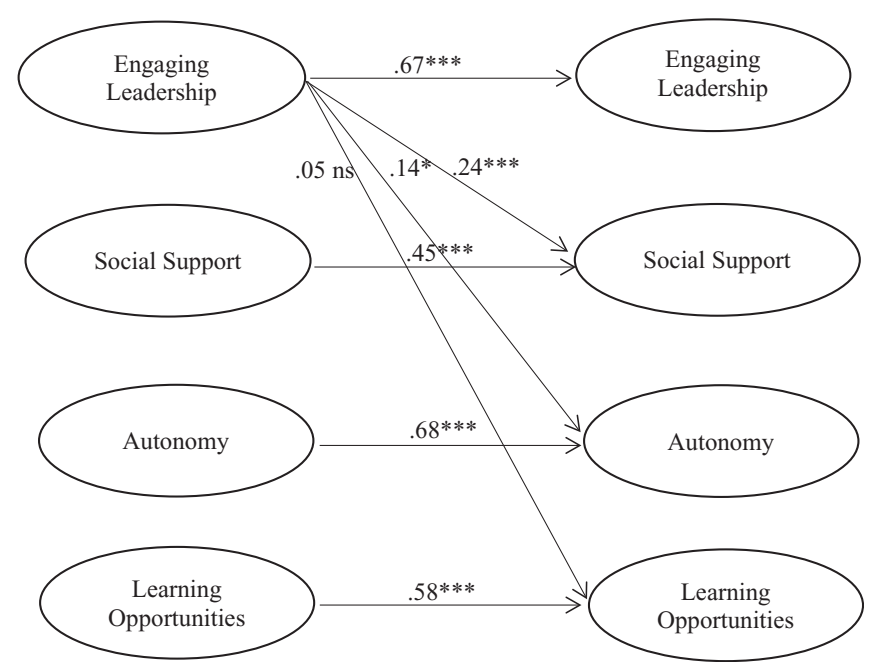

Fig. 2. Causal model with $\mathrm{T} 1$ engaging leadership and $\mathrm{T} 2$ job resources $(\mathrm{N}=273)$. $\chi^{2}=907.49 ; \mathrm{df}=551 ; \mathrm{CFI}=0.95 ; \mathrm{TLI}=0.95 ; \mathrm{RMSEA}=0.049$.

Time 1

Time 2

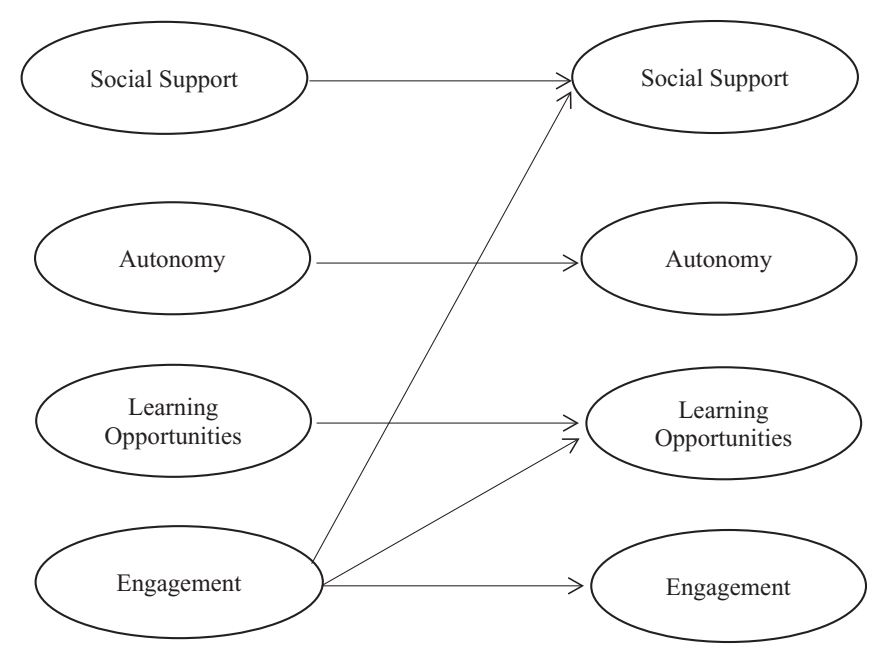

Fig. 3. Reversed causation model with $\mathrm{T} 1$ engagement and $\mathrm{T} 2$ job resources $(\mathrm{N}=273)$. $\chi^{2}=319.99 ; \mathrm{df}=221 ; \mathrm{CFI}=0.97 ; \mathrm{TLI}=0.97 ; \mathrm{RMSEA}=0.041$.

leadership predicted social support and autonomy but not learning opportunities one year later, thus providing partial support for Hypothesis 1 . Contrary to our expectations, the reversed causation model (i.e. work engagement predicting job resources) fit the data better than the causal model (i.e. job resources predicting work engagement); hence Hypothesis 2 was not supported.

\section{Discussion}

The main goal of this study was to provide longitudinal evidence for the links between engaging leadership, job resources and employee work engagement. In doing so, we integrated insights from literature about leadership and job characteristics (Nielsen et al., 2008; Piccolo \& Colquitt, 2006; Schaufeli, 2015) that helped us explain the processes underlying the relationship between a motivational leadership style (i.e. engaging leadership) and employee work engagement.

The results partially supported our conceptual model. Specifically, two of the three job resources at T2 - autonomy and social support from colleagues (but not learning opportunities) - were predicted by engaging leadership at $\mathrm{T} 1$ when tested across a oneyear time interval. However, job resources at T1 did not predict work engagement at T2; instead, the reversed causation model delivered the best fit to the data (i.e. work engagement at T1 increased perceptions of job resources at T2).

Our results have important implications because they show that engaging leaders are capable of fostering job resources, such as social support and autonomy, which are known to be precious for employee well-being (Hakanen et al., 2008; Weigl et al., 2010). Moreover, high levels of work engagement may lead to more job resources, which might either be due to perceiving more resources in the work environment (De Beer, Rothmann, \& Mostert, 2016) or to successful job crafting (Tims, Bakker, Derk, \& Van Rhenen, 2013).

\subsection{Theoretical contributions}

The goal of this study was to test cross-lagged relationships between engaging leadership, job resources and work engagement by means of a two-wave full panel design with a one-year time lag. First, following the recommendations of Cole and Maxwell (2003), we conducted a series of analyses intended to establish the direction of the relationships between the study concepts. The results largely supported the hypothesised causal direction between engaging leadership and perceived job resources but provided no evidence for effects streaming from job resources to work engagement (an effect largely supported by extant JD-R model research), after controlling for baseline autoregressive relationships. Second, by examining the relationships in our model across a one-year period, we were able to test whether this time lag is appropriate for the hypothesised relationships to unfold. It was necessary to validate our study model across time because research on engaging leadership has only started to reveal the effectiveness of this leadership style in enhancing valuable employee outcomes (Schaufeli, 2015).

To date, owing to its predominantly cross-sectional nature, the existing research on engaging leadership and employee outcomes has not been able to provide evidence for the directionality of the hypothesised relationships. To outline the contributions of this study, we will pay attention to the causal effects between engaging leadership and job resources, and between job resources and engagement, and will discuss the appropriateness of the time lag we used.

Our findings show that engaging leadership increases employee experiences of social support from colleagues and autonomy one year later, thereby confirming the assumption that a leader who inspires, strengthens and connects employees helps them perceive more resources in their environment. This may be because such leaders enable employees to more easily identify and more successfully craft these resources (Shuck \& Herd, 2012). Our results largely corroborate previous findings on engaging leadership and positive employee outcomes (Schaufeli, 2015); we also added to the limited knowledge on temporal effects by studying how they unfold over a period of one year. The choice of this specific time lag was informed by prior research on transformational leadership, job characteristics and employee well-being (De Lange, 2005; Nielsen et al., 2008). Extant research has indicated that time lags ranging between 8 and 18 months may be most appropriate for measuring the relationships hypothesised in our model (De Lange, 2005; Dormann \& Zapf, 1999, 2002; Nielsen et al., 2008). Also, from a theoretical point of view, it seems likely that a minimum of several 
months is needed for employees to be able to experience the full range of the leader's behaviours and for these leaders' behaviours to impact relevant job outcomes (e.g. job resources). In sum, our results strongly suggest that an engaging leadership style may have a prolonged impact on employee perceptions of social support from colleagues and autonomy. This finding is important because it enhances awareness of the long-lasting benefits of this leadership style for employees and, by extension, for organisations.

Despite our expectation that engaging leadership can enhance employee perceptions of learning opportunities, we found no support for this hypothesis. To better understand this null finding, we scrutinised our sample more closely. The demographic characteristics revealed that the majority of the participants (54.2\%) had been employed in their current job for less than four years. In addition, about a quarter of them (25.6\%) worked part-time (i.e. $30 \mathrm{~h}$ or less per week). As noted earlier, to filter out potential interference of the sample's demographic characteristics on the study findings, we tested our models with several control variables. Results showed that only the variable 'number of hours spent at work' was positively and significantly linked to learning opportunities, indicating that employees who worked longer hours enjoyed more developmental opportunities than their colleagues who were employed on a part-time basis. Scholars (e.g. Billett, 1999; Tam, 1997) have suggested that contingent workers (i.e. part-time and contractual employees) may feel more constrained in realising their career aspirations because they are given fewer developmental opportunities. As the hospitality sector often relies on a flexible workforce, the above demographics might provide a clue to our null finding. Specifically, employees who consider their work in the catering industry to be a temporary job rather than a lifelong career path might not be inclined to search for and utilise the developmental opportunities that arise in their daily work.

Also, it is common for organisations to invest in their employees' development (i.e. provide budgets for training) in proportion to the number of hours they actually work. Employees who spend more time at work every week and remain employed at the same organisation for longer are more likely to be viewed by their employer as assets worth investing in (Kyndt, Govaerts, Dochy, \& Baert, 2011); hence, HR policies for professional development might be directed at employees who are more invested in their work and more loyal to their organisation. Moreover, employees who enjoy a shorter workweek are likely to be exposed to fewer on-the-job learning opportunities simply because they spend less time at work.

Finally, even though we found no significant link between the variable 'occupational level' and learning opportunities, considering the over-representation of low-qualified jobs in the hospitality sector, it is possible that the relationship between engaging leadership and learning opportunities would be significant if tested on a larger sample in which most employees are white-collar workers. Empirical evidence indicates that compared to whitecollar workers, employees who work in low-qualified jobs (i.e. employees with low levels of education) are afforded fewer developmental opportunities (Boeren, Nicaise, \& Baert, 2010; Greenhalgh \& Mavrotas, 1994, pp. 579-604; Kyndt, Dochy, \& Nijs, 2009; Tharenou, 1997) and might be less successful in identifying or crafting such opportunities themselves. Research has shown that since low-skilled workers are less involved in formal vocational training (Greenhalgh \& Mavrotas, 1994, pp. 579-604; Tharenou, 1997) and enter the labour market in less favourable positions, they might be more easily trapped in situations with limited career options and developmental opportunities (i.e. 'the low skill trap', Burdett \& Smith, 2002).

On a similar note, owing to the low learning efficacy and the accumulation of negative educational experiences, low-qualified employees may be less willing to participate in training (Illeris, 2006; Kyndt et al., 2009). The accumulation of negative learning experiences can lead to a lower willingness to learn (i.e. learning intentions), which would limit one's career prospects; having fewer career options and remaining 'caught' in the low-skill trap implies less access to learning opportunities, resulting in a vicious 'development-restrictive' circle in the long run (Burdett \& Smith, 2002). Although constrained developmental and career opportunities can be disadvantageous for employees, organisations might not perceive the added value of investing in the competence development of their low-skilled workforce, because such investment might be considered unlikely to increase the organisation's revenue or to help retain employees in their current jobs (Asplund \& Salverda, 2004; Krueger \& Rouse, 1998).

Altogether, in the long run a variety of factors - for instance, employment conditions and changes in the work context (e.g., new team, changes in personal and team goals, lay-offs) - might be important precursors of employee vocational development and engagement experiences (Kyndt et al., 2009; Petrou, Demerouti, \& Schaufeli, 2018). Importantly, these conditions are likely to affect access to learning opportunities and employee work engagement, even beyond the positive influence an engaging leader might have on employees.

In this study, we did not find a cross-lagged effect from job resources on employee work engagement. Model comparison showed that the reversed model (i.e. work engagement predicting job resources) best fit the data, indicating the importance of engagement as a positive affective state that can engender positive context experiences (i.e. increased job resources). Altogether, our results suggest that engaging leadership might not influence employee work engagement directly or through job resources. Different reasons might account for this.

It is, for instance, possible that a one-year time lag might be too long to capture the potential effects of leadership styles (e.g. engaging leadership) on employee outcomes (i.e. engagement); this is because many aspects of the work context, beyond the three resources included in our study, might have changed in one year's time. For instance, changes in team composition, working conditions or direct supervision might counteract or even taint the potential beneficial effect of engaging leadership on employee work engagement.

Even though leadership characteristics and behaviours tend to be relatively stable across time (Seppälä et al., 2015), the impact of engaging leadership on employee resources and work engagement might be best studied with a shorter time lag. For instance, Dormann and Griffin (2015) suggested using 'shortitudinal pilot studies' with quite short lags that help researchers design an optimally spaced panel study. Such 'shortitudinal' studies provide essential information about the expected distribution of causal effects over time. Moreover, the idea of shorter time lags is in line with recent findings (Hetland et al., 2018) that indicate that supportive leadership can influence employee outcomes on a day-today basis.

Even though we did not formulate specific hypotheses for the reversed causation assumptions (i.e. work engagement predicting job resources), the established significant result is not unprecedented. Over the past decade, research on the JD-R model (De Lange, De Witte, \& Notelaers, 2008) delivered findings that support both a causal and a reversed effect between job resources and employee work engagement (De Beer, Pienaar, \& Rothmann, 2013; Reis, Hoppe, \& Schröder, 2015; Xanthopoulou, Bakker, Demerouti, \& Schaufeli, 2009). To theoretically explain the processes between job resources and employee engagement, scholars often resorted to one of the key tenets of the Conservation of Resources Theory (COR; Hobfoll, 2011): the notion of 'upward gain spirals' (i.e. 
the accumulation of resources enhances individuals' well-being, which in turn provides conditions for further resource gains).

Yet, explaining the reciprocal relationship between job resources and employee engagement through the lens of COR has not been unchallenged. Some scholars (Biggs, Brough, \& Barbour, 2014) have suggested that since engagement and job resources tend to be quite stable characteristics (Seppälä et al., 2015), actual differences across time are therefore not easily observed. Subsequently, the only claim that can be made based on the established reciprocal relationships is that job resources and engagement can fuel one another, contributing to a 'self-correcting spiral' rather than to an upward spiral owing to accumulative process (Biggs et al., 2014).

However, our results (i.e. work engagement enhancing future perceptions of job resources) do not imply circular or accumulative processes (as suggested by COR); the established unidirectional effect between work engagement and job resources aligns closely with one of the core propositions of broaden-and-build theory (Fredrickson, 2001). Specifically, this theory suggests that a positive affective state - such as work engagement - can broaden one's attention, cognition and action, thereby enabling the individual to build physical, intellectual and psychological resources.

In light of these theoretical underpinnings, it stands to reason that work engagement may enhance job resources in two ways. First, work engagement as a positive affect may broaden individuals' perceptions and cognitions of their environment, thereby enabling them to more efficiently identify the resources around them. Second, employees who experience a positive affective state (e.g. being engaged) may be better equipped (cognitively and emotionally) and more strongly motivated to successfully undertake efforts in crafting job resources (Beer, Rothman, \& Mostert, 2016; Halbesleben, 2011). Engaged employees, therefore, may be more capable of successfully shaping a supportive social network, job autonomy and opportunities for development at work in line with their individual needs. Presumably, a positive work-based affect can trigger individuals to change their work environment even more so than the environment can affect employee engagement (De Beer et al., 2016; Yu, 2009). Altogether, engaged employees make better use of the available resources because they are more successful in identifying and acquiring resources in their job, and are more successful in crafting new ones (De Beer et al., 2016).

Surprisingly, we found no evidence that job resources can impact work engagement, which implies that no claims can be made for a mediation effect of job resources in the relationship between engaging leadership and employee engagement. The selected one-year time lag in combination with the stability of the construct work engagement may account for the lack of support for our second hypothesis. A longer time lag is better suited for studying the influence of work engagement on job resources, compared to the time needed for tapping into the opposite (environment influencing engagement) effect (Weigl et al., 2010), because it takes longer for an individual to be able to change features of the environment than for the environment to affect the individual's well-being.

In addition, recent research (Seppälä et al., 2015) has showed that work engagement is a relatively stable characteristic and as such it might be a stronger predictor of the work environment (than the other way around) when tested over a prolonged period of time. In our study, work engagement remained very stable between T1 and T2 (with an autoregressive path coefficient of 0.76; Fig. 3), which might have led to an underestimation of the causal effect (from job resources to engagement).

The accumulated body of research (De Beer et al., 2013; Reis et al., 2015; Xanthopolou et al., 2009) on job resources and employee well-being has shown, beyond doubt, that job resources are key for employee work engagement. Altogether, it is conceivable that the favourable effect of job resources on work engagement (or the lack thereof) will be felt much sooner than one year. A lack of valuable resources (i.e. social support, job autonomy and opportunities for learning and personal growth) might almost instantly set negative cognitive and emotional processes in motion, lowering one's motivation and thereby negatively affecting engagement experiences in a relatively short time frame (Bakker \& Sanz-Vergel, 2013). The notion that a shorter time lag might be more appropriate for testing the effect of job resources on work engagement, while a longer period of time might be better suited for studying the reversed effects, accords with evidence from prior longitudinal research (Weigl et al., 2010). Also, diary studies (Bakker \& Sanz-Vergel, 2013) have convincingly shown that work engagement is particularly susceptible to fluctuations in job resources when studied on a daily basis.

\subsection{Limitations}

There are some limitations to the current study. First, owing to the homogeneity of the data (i.e. collected among employees working in one particular hotel chain) the generalisability of our findings and conclusions is limited to employees working in the hospitality industry. Therefore, caution is called for when applying our conclusions to other populations. To overcome this limitation, future research could test our model on data obtained from a heterogeneous sample that includes different industries and occupational groups.

Second, the data for this study was collected by means of selfreported measures. This may raise a concern for common method bias and measurement error, because the use of self-reports may result in inflated estimation of the study effects (Frese \& Zapf, 1994). However, Spector (2006) argued against this concern by pointing out that common method bias issues are usually overstated in this kind of survey research. Moreover, in line with Conway and Lance (2010), it is appropriate to use self-reports to study perceptions of job characteristics and occupational well-being in psychological research. This is because experiences of the work context and of occupational well-being are subjective by their very nature and are thus best measured by tapping into individuals' perceptions. To test the robustness of our model, future studies might wish to replicate it using data collected from various actors (e.g. evaluations from colleagues, supervisors and external parties) when measuring constructs such as engaging leadership, job resources and work engagement (Mazetti, Schaufeli, \& Guglielmi, 2018).

Third, in the current contribution we operationalized learning opportunities with a scale that taps in to employee perceptions of their job as conducive to successful learning (i.e., 'in my work I regularly learn new things'). Although providing employees with ample opportunities for professional development might be imperative to their effective learning, the opportunities as such do not guarantee a successful acquisition of new competences. Importantly, as every learning situation entails some extent of ambiguity regarding the learning outcomes, when learning opportunities arise, they might contribute towards either feelings of competency (if employees feel that they can successfully obtain new knowledge and skills) or feelings of incompetency and underachievement (if employees anticipate failure to achieve the learning objectives). Even though successful learning experiences can enhance one's sense of competency, leadership style alone might not be sufficient to ensure successful learning. To enable a more precise testing of the relationship between engaging leadership and learning opportunities, future studies should operationalize learning opportunities by using a scale that focuses on the opportunities as such instead of tapping into the (presumably 
favourable) outcomes of the learning processes.

Fourth, attrition analyses revealed that dropout in our sample was not completely at random. Employees who reported lower levels of autonomy at T1 had a higher dropout rate at T2. Even though this finding is not unprecedented for research on job resources (Bakker \& Demerouti, 2007; Mäkikangas, Bakker, Aunola, \& Demerouti, 2010), we cannot be certain about the reason such a selective bias might have occurred. It is, for instance, possible that employees who perceived lower levels of autonomy at T1 had left the company by $\mathrm{T} 2$ because they were not satisfied with their working conditions. Another possible explanation for this selective non-response might be found in employees' perceptions of psychological contract breach. Employees may have perceived their participation in the online survey as a citizenship behaviour towards their employer; such behaviour would be considered an effort to keep the exchange relationship with the organisation in balance (Organ, 1988; Organ \& Ryan, 1995). However, if employees appraise the low levels of autonomy as a breach of their expectations about the work context, they are likely to withdraw from citizenship behaviours that might benefit the organisation and thus not take part in the survey at $\mathrm{T} 2$.

Importantly, it is possible that the lack of significant effect from autonomy on work engagement might be to some extent attributed to a restriction of the range associated with the non-random dropout. Non-random dropout might imply that the study findings about autonomy are sample-dependent and thus might not be replicated if tested on a sample where dropout was random. Since we cannot rule out the possibility that dropouts caused by low autonomy caused the link between autonomy and engagement to be underestimated, we strongly recommend that future studies replicate our findings using different samples (that are not affected by selective dropout).

Finally, the validity of our model was tested on data collected at two points in time with a one-year lag between the measurements. Two issues are associated with this research design. First, for mediation effects to be examined, a research design incorporating a minimum of three-wave data is recommended (Cole \& Maxwell, 2003). Thus, one avenue for future research would be to test our conceptual model on three-wave data. However, in this study we followed the approach recommended by Cole and Maxwell (2003) for testing half-longitudinal design, which allowed us to test our assumptions for causality. Second, as outlined above, one could argue that a shorter time lag (e.g. a few weeks or months) might be more suited to testing the hypothesised relationship between job resources and work engagement. Moreover, it is possible that the optimal time lag for measuring the relationship between job resources and work engagement varies depending on the specific resource. Exposure to some resources might affect employee engagement faster than exposure to others.

\subsection{Conclusions and implications for practice}

This study extends existing knowledge on engaging leadership and its motivational properties, by showing that an engaging leader may boost employees' positive perceptions of their job context. Our results indicated that a leadership style that includes inspiring, strengthening and connecting employees might play a key role in shaping employees' perceptions of their work context as resourceful (e.g., by enhancing perceptions of available autonomy and social support). Importantly, as a suchlike positive leadership style is deemed to be effective in creating resourceful (i.e., autonomy and social support nurturing) work environments, it is also to some extent - expected to provide an alternative to costly job redesign interventions (Nielsen et al., 2008). Organisations may facilitate this by providing leadership development programmes that promote engaging leadership in daily interactions with employees. Training managers to master the particular skill set required to support employee work engagement seems practical because empirical evidence from the past decade has shown that leadership behaviours are malleable and subject to change by means of professional training (Jackson \& Lindsay, 2010; Nielsen, Randall, \& Christensen, 2010; Parry \& Sinha, 2005).

Contrary to our expectations, we found no evidence that engaging leadership stimulates employees in utilizing more learning opportunities. Possibly this null finding was due to an implicit assumption (inherent to our learning opportunities scale) that learning opportunities would typically result in successful learning outcomes. Shaping successful learning experiences, however, might extend beyond the power of the leader, because learning experiences are highly dependent on the learner's personal characteristics (e.g., learning self-efficacy; Noe, Tews, \& Marand, 2013) and capacity or energy to engage in the learning process (Holman \& Wall, 2002). The latter was also supported by the significant cross-lagged effect from employee engagement to employee perceived learning opportunities established in this study, indicating that individuals might be better able to identify and use learning situations that arise at work, when they experience a positive work-related affective state (i.e., being engaged).

In line with the tenets of the broaden-and-built theory (Fredrickson, 2001), the second major finding of our study shows that those employees who are engaged (i.e., in a state of positive affect) experiences a more positive and resourceful work context across time. Organisations that place a high value on creating resourceful work environments are well advised to foster employee engagement and to encourage managers to lead by the principles of engaging leadership. Presumably organisational initiatives aimed at increasing employee engagement will additionally lead to an increase in their perceptions of autonomy, social support and learning opportunities; two of these three job characteristics (i.e., autonomy and social support) will, in turn, feed back into employee engagement, contributing ultimately to a 'self-correcting spiral' of resources and well-being (Biggs et al., 2014).

\section{References}

Asplund, R., \& Salverda, W. (2004). Introduction: Company training and services with a focus on low skills. International Journal of Manpower, 25(1), 8-16.

Bakker, A. B., \& Demerouti, E. (2007). The job demands-resources model: State of the art. Journal of Managerial Psychology, 22, 309-328.

Bakker, A. B., Demerouti, E., \& Schaufeli, W. B. (2005). The crossover of burnout and work engagement among working couples. Human Relations, 58, 661-689.

Bakker, A. B., Hakanen, J. J., Demerouti, E., \& Xanthopoulou, D. (2007). Job resources boost work engagement, particularly when job demands are high. Journal of Educational Psychology, 99(2), 274.

Bakker, A. B., \& Sanz-Vergel, A. I. (2013). Weekly work engagement and flourishing: The role of hindrance and challenge job demands. Journal of Vocational Behavior, 83(3), 397-409.

Bamford, M., Wong, C. A., \& Laschinger, H. (2013). The influence of authentic leadership and areas of work life on work engagement of registered nurses. Journal of Nursing Management, 21(3), 529-540.

Bass, B. M. (1985). Leadership and performance beyond expectations. New York: Free Press.

Bass, B. M., \& Riggio, R. E. (2006). Transformational leadership ( $2^{\text {nd }}$ ed.). Mahwah, NJ: Lawrence Erlbaum.

Biggs, A., Brough, P., \& Barbour, J. P. (2014). Strategic alignment with organizational priorities and work engagement: A multi-wave analysis. Journal of Organizational Behavior, 35(3), 301-317.

Billett, S. (1999). Workplace affordances and individual engagement at work. Research to Reality. Putting VET Research to Work, 210.

Boeren, E., Nicaise, I., \& Baert, H. (2010). Theoretical models of participation in adult education: The need for an integrated model. International Journal of Lifelong Education, 29(1), 45-61.

Boud, D., \& Middleton, H. (2003). Learning from others at work: Communities of practice and informal learning. Journal of Workplace Learning, 15(5), 194-202.

Breevaart, K., Bakker, A., Hetland, J., Demerouti, E., Olsen, O. K., \& Espevik, R. (2014). Daily transactional and transformational leadership and daily employee engagement. Journal of Occupational and Organizational Psychology, 87(1), 
$138-157$.

Brown, M. E., Treviño, L. K., \& Harrison, D. A. (2005). Ethical leadership: A social learning perspective for construct development and testing. Organizational Behavior and Human Decision Processes, 97(2), 117-134.

Burdett, K., \& Smith, E. (2002). The low skill trap. European Economic Review, 46(8), 1439-1451.

Byrne, B. M. (2013). Structural equation modeling with Mplus: Basic concepts, applications, and programming. Routledge.

Carasco-Saul, M., Kim, W., \& Kim, T. (2015). Leadership and employee engagement: Proposing research agendas through a review of literature. Human Resource Development Review, 14(1), 38-63.

Cole, D. A., \& Maxwell, S. E. (2003). Testing mediational models with longitudinal data: Questions and tips in the use of structural equation modeling. Journal of Abnormal Psychology, 112(4), 558-577.

Conway, J. M., \& Lance, C. E. (2010). What reviewers should expect from authors regarding common method bias in organizational research. Journal of Business and Psychology, 25, 325-334.

De Beer, L. T., Pienaar, J., \& Rothmann, S., Jr. (2013). Investigating the reversed causality of engagement and burnout in job demands-resources theory. $S A$ Journal of Industrial Psychology, 39(1), 01-09.

De Beer, L. T., Rothmann, S., Jr., \& Mostert, K. (2016). The bidirectional relationship between person-job fit and work engagement: A three-wave study. Journal of Personnel Psychology, 15(1), 4.

De Lange, A. H. (2005). What about causality? Examining longitudinal relations between work characteristics and mental health. Unpublished doctoral dissertation. Nijmegen: Radboud University Nijmegen.

De Lange, A. H., De Witte, H., \& Notelaers, G. (2008). Should I stay or should I go? Examining longitudinal relations among job resources and work engagement for stayers versus movers. Work \& Stress, 22(3), 201-223.

Deci, E. L., \& Ryan, R. M. (2000). The" what" and" why" of goal pursuits: Human needs and the self-determination of behavior. Psychological Inquiry, 11(4), 227-268.

DeCuypere, A., \& Schaufeli, W. B. (2018). Positive leadership styles and engagement: A meta-analyses and review (Manuscript under review).

Demerouti, E., Bakker, A. B., Nachreiner, F., \& Schaufeli, W. B. (2001). The job demands-resources model of burnout. Journal of Applied Psychology, 86(3), 499.

Dormann, C., \& Griffin, M. A. (2015). Optimal time lags in panel studies. Psychological Methods, 20(4), 489.

Dormann, C., \& Zapf, D. (1999). Social support, social stressors at work, and depressive symptoms: Testing for main and moderating effects with structural equations in a three-wave longitudinal study. Journal of Applied Psychology, 84 $874-884$.

Dormann, C., \& Zapf, D. (2002). Social stressors at work, irritation, and depressive symptoms: Accounting for unmeasured third variables in a multi-wave study. Journal of Occupational and Organizational Psychology, 75, 33-58.

Fernet, C., Austin, S., \& Vallerand, R. J. (2012). The effects of work motivation on employee exhaustion and commitment: An extension of the JD-R model. Work \& Stress, 26(3), 213-229.

Fredrickson, B. L. (2001). The role of positive emotions in positive psychology: The broaden-and-build theory of positive emotions. American Psychologist, 56(3), $218-226$.

Frese, M., \& Zapf, D. (1994). Methodological issues in the study of work stress: Objective vs subjective measurement of work stress and the question of longitudinal studies. In C. L. Cooper, \& I. T. Robertson (Eds.), Causes, coping and consequences of stress at work (pp. 375-411). Oxford, England: John Wiley \& Sons.

Ghadi, M., Fernando, M., \& Caputi, P. (2013). Transformational leadership and work engagement: The mediating effect of meaning in work. The Leadership \& Organization Development Journal, 34(6), 532-550.

Goodman, J. S., \& Blum, T. C. (1996). Assessing the non-random sampling effects of subject attrition in longitudinal research. Journal of Management, 22(4), 627-652.

Greenhalgh, C., \& Mavrotas, G. (1994). The role of career aspirations and financial constraints in individual access to vocational training. Oxford Economic Papers.

Hakanen, J. J., Schaufeli, W. B., \& Ahola, K. (2008). The job demands-resources model: A three-year cross-lagged study of burnout, depression, commitment, and work engagement. Work \& Stress, 22(3), 224-241.

Halbesleben, J. R. (2011). The consequences of engagement: The good, the bad, and the ugly. European Journal of Work \& Organizational Psychology, 20(1), 68-73.

Hetland, H., Hetland, J., Schou Andreassen, C., Pallesen, S., \& Notelaers, G. (2011). Leadership and fulfillment of the three basic psychological needs at work. Career Development International, 16(5), 507-523.

Hetland, J., Hetland, H., Bakker, A. B., \& Demerouti, E. (2018). Daily transformational leadership and employee job crafting: The role of promotion focus. European Management Journal, 36(6), 746-756.

Hobfoll, S. E. (2011). Conservation of resource caravans and engaged settings. Journal of Occupational and Organizational Psychology, 84(1), 116-122.

Holman, D. J., \& Wall, T. D. (2002). Work characteristics, learning-related outcomes, and strain: A test of competing direct effects, mediated, and moderated models. Journal of Occupational Health Psychology, 7(4), 283-301.

Hu, Q., Schaufeli, W. B., \& Taris, T. W. (2011). The Job Demands-Resources model: An analysis of additive and joint effects of demands and resources. Journal of Vocational Behavior, 79(1), 181-190.

Illeris, K. (2006). Lifelong learning and the low-skilled. International Journal of Lifelong Education, 25(1), 15-28.
Jackson, R. J., \& Lindsay, D. R. (2010). Lessons for experience: Why wait? Industrial and Organizational Psychology, 3, 48-51.

Karasek, R., \& Theorell, T. (1990). Healthy work: Stress, productivity, and the reconstruction of working life. New York: Basic Books.

Krueger, A., \& Rouse, C. (1998). The effect of workplace education on earnings, turnover, and job performance. Journal of Labor Economics, 16(1), 61-94.

Kyndt, E., Dochy, F., \& Nijs, H. (2009). Learning conditions for non-formal and informal workplace learning. Journal of Workplace Learning, 21(5), 369-383.

Kyndt, E., Govaerts, N., Dochy, F., \& Baert, H. (2011). The learning intention of lowqualified employees: A key for participation in lifelong learning and continuous training. Vocations and Learning, 4(3), 211-229.

Lee, R. T., \& Ashforth, B. E. (1996). A meta-analytic examination of the correlates of the three dimensions of job burnout. Journal of Applied Psychology, 81(2), $123-133$.

Liden, R. C., Wayne, S. J., Liao, C., \& Meuser, J. D. (2014). Servant leadership and serving culture: Influence on individual and unit performance. Academy of Management Journal, 57(5), 1434-1452.

Mäkikangas, A., Bakker, A. B., Aunola, K., \& Demerouti, E. (2010). Job resources and flow at work: Modelling the relationship via latent growth curve and mixture model methodology. Journal of Occupational and Organizational Psychology, 83(3), 795-814.

Mazetti, G., Schaufeli, W. B., \& Guglielmi, D. (2018). Are workaholism and work engagement in the eye of the beholder? A multirater perspective on different forms of working hard. European Journal of Psychological Assessment, 34, 30-40.

Muthén, L. K., \& Muthén, B. O. (2010). Mplus user's guide: Statistical analysis with latent variables: User's guide. Muthén \& Muthén.

Nielsen, K., Randall, R., \& Christensen, K. B. (2010). Does training managers enhance the effects of implementing team-working? A longitudinal, mixed methods field study. Human Relations, 63, 1719-1741.

Nielsen, K., Randall, R., Yarker, J., \& Brenner, S. O. (2008). The effects of transformational leadership on followers' perceived work characteristics and psychological well-being: A longitudinal study. Work \& Stress, 22(1), 16-32.

Noe, R. A., Tews, M. J., \& Marand, A. D. (2013). Individual differences and informal learning in the workplace. Journal of Vocational Behavior, 83(3), 327-335.

Oldham, G. R. (1996). Job design. In C. L. Cooper, \& I. T. Robertson (Eds.), Vol. 11 International review of industrial and organizational psychology (pp. 33-60). Chichester, UK: Wiley.

Organ, D. W. (1988). Organizational citizenship behavior: The good soldier syndrome Lexington Books/DC Heath and Com.

Organ, D. W., \& Ryan, K. (1995). A meta-analytic review of attitudinal and dispositional predictors of organizational citizenship behavior. Personnel Psychology, 48(4), 775-802.

Parry, K. W., \& Sinha, P. N. (2005). Researching the trainability of transformational organizational leadership. Human Resource Development International, 8, $165-183$.

Perko, K., Kinnunen, U., Tolvanen, A., \& Feldt, T. (2016). Investigating occupationa well-being and leadership from a person-centred longitudinal approach: Congruence of well-being and perceived leadership. European Journal of Work \& Organizational Psychology, 25(1), 105-119.

Petrou, P., Demerouti, E., \& Schaufeli, W. B. (2018). Crafting the change: The role of employee job crafting behaviors for successful organizational change. Journal of Management, 44(5), 1766-1792.

Philippaers, K., De Cuyper, N., Forrier, A., Vander Elst, T., \& De Witte, H. (2016). Perceived employability in relation to job performance: A cross-lagged study accounting for a negative path via reduced commitment. Scandinavian Journal of Work and Organizational Psychology, 1(1), 1-15.

Piccolo, R. F., \& Colquitt, J. A. (2006). Transformational leadership and job behaviors: The mediating role of core job characteristics. Academy of Management Journal, 49(2), 327-340.

Reis, D., Hoppe, A., \& Schröder, A. (2015). Reciprocal relationships between resources, work and study engagement, and mental health: Evidence for gain cycles. European Journal of Work \& Organizational Psychology, 24(1), 59-75.

Ryan, R. M., \& Deci, E. L. (2001). On happiness and human potentials: A review of research on hedonic and eudaimonic well-being. Annual Review of Psychology, 52(1), 141-166.

Schaufeli, W. B. (2015). Engaging leadership in the job demands-resources model Career Development International, 20(5), 446-463.

Schaufeli, W. B., \& Bakker, A. B. (2004). Job demands, job resources, and their relationship with burnout and engagement: A multi-sample study. Journal of Organizational Behavior, 25(3), 293-315.

Schaufeli, W. B., Salanova, M., González-Romá, V., \& Bakker, A. B. (2002). The measurement of engagement and burnout: A two sample confirmatory factor analytic approach. Journal of Happiness Studies, 3(1), 71-92.

Schaufeli, W. B., Shimazu, A., Hakanen, J., Salanova, M., \& De Witte, H. (2017). An ultra-short measure for work engagement: The UWES-3. Validation across five countries. European Journal of Psychological Assessment.

Seppälä, P., Hakanen, J., Mauno, S., Perhoniemi, R., Tolvanen, A., \& Schaufeli, W. (2015). Stability and change model of job resources and work engagement: A seven-year three-wave follow-up study. European Journal of Work \& Organizational Psychology, 24(3), 360-375.

Shuck, B., \& Herd, A. M. (2012). Employee engagement and leadership: Exploring the convergence of two frameworks and implications for leadership development in HRD. Human Resource Development Review, 11(2), 156-181.

Skakon, J., Nielsen, K., Borg, V., \& Guzman, J. (2010). Are leaders' well-being, behaviours and style associated with the affective well-being of their employees? 
A systematic review of three decades of research. Work \& Stress, 24(2), 107-139. Spector, P. E. (2006). Method variance in organizational research truth or urban legend? Organizational Research Methods, 9(2), 221-232.

Spector, P. E., \& Brannick, M. T. (2011). Methodological urban legends: The misuse of statistical control variables. Organizational Research Methods, 14(2), 287-305.

Tam, M. (1997). Part-time employment: A bridge or a trap? USA: Aldershot: Brookfield.

Taris, T., \& Kompier, M. (2006). Games researchers play - extreme group analysis and mediation analysis in longitudinal occupational health research. Scandinavian Journal of Work, Environment \& Health, 32, 463-472.

Tharenou, P. (1997). Determinants of participation in training and development. Journal of Organizational Behavior, 4, 15 .

Tims, M., Bakker, A. B., Derks, D., \& Van Rhenen, W. (2013). Job crafting at the team and individual level: Implications for work engagement and performance. Group \& Organization Management, 38(4), 427-454.

Tims, M. Bakker A. B. \& Xanthopoulou, D. (2011). Do transformational leaders enhance their followers' daily work engagement? The Leadership Quarterly, 22(1), 121-131.

Tuckey, M. R., Bakker, A. B., \& Dollard, M. F. (2012). Empowering leaders optimize working conditions for engagement: A multilevel study. Journal of Occupationa Health Psychology, 17(1), 15.

Van Knippenberg, D., \& Sitkin, S. B. (2013). A critical assessment of charismatictransformational leadership research: Back to the drawing board? The Academy of Management Annals, 7(1), 1-60.

Van den Broeck, A., Vansteenkiste, M., De Witte, H., \& Lens, W. (2008). Explaining the relationships between job characteristics, burnout, and engagement: The role of basic psychological need satisfaction. Work \& Stress, 22(3), 277-294. van Veldhoven, M., \& Meijman, T. F. (1994). Het meten van psychosociale arbeidsbelasting met een vragenlijst: De vragenlijst beleving en beoordeling van de arbeid (VBBA) [the measurement of psychosocial job demands with a questionnaire: The questionnaire on the experience and evaluation of work (QEEW)]. Amsterdam: Nederlands Instituut voor Arbeidsomstandigheden.

Vincent-Höper, S., Muser, C., \& Janneck, M. (2012). Transformational leadership, work engagement, and occupational success. Career Development International, 17(7), 663-682.

Walumbwa, F. O., Wang, P. Wang, H., Schaubroeck, J., \& Avolio, B. J. (2010). Psychological processes linking authentic leadership to follower behaviors. The Leadership Quarterly, 21(5), 901-914.

Weigl, M., Hornung, S., Parker, S. K., Petru, R., Glaser, J., \& Angerer, P. (2010). Work engagement accumulation of task, social, personal resources: A three-wave structural equation model. Journal of Vocational Behavior, 77(1), 140-153.

Xanthopoulou, D., Bakker, A. B., Demerouti, E., \& Schaufeli, W. B. (2009). Reciprocal relationships between job resources, personal resources, and work engagement. Journal of Vocational Behavior, 74(3), 235-244.

Yu, K. Y. T. (2009). Affective influences in person-environment fit theory: Exploring the role of affect as both cause and outcome of P-E fit. Journal of Applied Psychology, 94, 1210-1226.

Zhang, X., \& Bartol, K. M. (2010). Linking empowering leadership and employee creativity: The influence of psychological empowerment, intrinsic motivation, and creative process management. Academy of Management Journal, 53(1), 107-128.

Zhu, W., Avolio, B. J., \& Walumbwa, F. O. (2009). Moderating role of follower characteristics with transformational leadership and follower work engagement. Group \& Organization Management, 34, 519-619. 